\title{
Persepsi tubuh negatif meningkatkan kejadian eating disorders pada remaja usia 15-19 tahun
}

\author{
Rachmannisa Shauma Aghna Syifa ${ }^{1}$ Pusparini $^{2}$
}

\begin{abstract}
ABSTRAK
\section{LATAR BELAKANG}

Eating disorders (gangguan makan) adalah suatu sindrom yang ditandai oleh pola makan yang menyimpang terkait dengan karakteristik psikologik yang berhubungan dengan makan, persepsi tubuh, dan berat badan. Pengaruh media massa dan tekanan dari sosiokultural bahwa seseorang bertubuh kurus adalah yang paling menarik dapat membuat seorang remaja memiliki persepsi tubuh negatif yang dapat memicu terjadinya eating disorders. Dalam satu dekade terakhir, prevalensi eating disorders di Asia Tengggara mengalami peningkatan dari 0,46\% menjadi $3,2 \%$ Tujuan dilakukannya penelitian ini adalah untuk menganalisis hubungan antara persepsi tubuh dengan eating disorders pada remaja usia 15-19 tahun.

\section{METODE}

Penelitian ini dilakukan pada bulan November 2017 menggunakan desain observasional analitik secara potong lintang (cross-sectional) yang mengikutsertakan 201 siswa SMA Global Islamic School, Jakarta Timur. Data dikumpulkan dengan cara wawancara menggunakan kuesioner. Pemilihan sampel dilakukan dengan metode simple random sampling, dan pengukuran meliputi status gizi (antropometri, Indeks Massa Tubuh), persepsi tubuh (Contour Drawing Figure Rating Scale) dan eating disorders (Eating Disorders Diagnostic Scale). Analisis data menggunakan Chi-Square dengan tingkat kemaknaan sebesar 0,05.
\end{abstract}

\section{HASIL}

Mayoritas responden mempunyai persepsi tubuh yang negatif (70,6\%). Responden yang mengalami eating disorders sebesar 52,7\%. Responden yang memiliki persepsi tubuh negatif sebagian besar mengalami eating disorders $(66,2 \%)$. Analisis Chi-Square menunjukkan adanya hubungan yang bermakna antara persepsi tubuh dengan eating disorders $(\mathrm{p}=0,000)$.

\section{KESIMPULAN}

Terdapat hubungan yang bermakna antara persepsi tubuh dan eating disorders. Perlu penanganan terhadap persepsi tubuh negatif sedini mungkin untuk mencegah terjadinya eating disorders pada remaja.

Kata kunci : persepsi tubuh, status gizi, remaja, eating disorders

\author{
${ }^{1}$ Program Studi Kedokteran, \\ Fakultas Kedokteran, \\ Universitas Trisakti \\ ${ }^{2}$ Departemen Patologi Klinik, \\ Fakultas Kedokteran, \\ Universitas Trisakti
}

\section{Korespondensi:}

Pusparini

Departemen Patologi Klinik

Fakultas Kedokteran Universitas

Trisakti, Jalan Kyai Tapa No. 260,

Grogol, Jakarta Barat.

Email: pusparini@trisakti.ac.id

J Biomed Kes 2018;1(1):18-25

DOI: 10.18051/JBiomedKes.2018.

v1.18-25

pISSN: 2621-539X / eISSN: 2621-5470

Artikel akses terbuka (open access) ini didistribusikan di bawah lisensi Creative Commons Attribution 4.0 International (CC-BY 4.0) 


\section{ABSTRACT}

\section{Negative body image increase risk of eating diorders in adolescent aged 15-19 years}

\section{BACKGROUND}

Eating disorder is a syndrome of a range of psychological disorders characterized by disturbed eating habits which often associates with body image. Body image is a person's perception, thoughts, and feelings of their physical self. The current media culture has been glorifying an image of unrealistic body standard that leads to negative body image among adolescents and can place a person at a greater risk of developing an eating disorder. Over the last decade, the prevalence of eating disorders in South-East Asia has been increased from $0.46 \%$ to $3.2 \%$. The objective of this study was to determine the association between body image and eating disorders among adolescent $15-19$ years of age.

\section{METHODS}

A cross-sectional design was performed involving 201 students of Global Islamic Senior High School, East Jakarta. Data was collected using questionnaires, body mass index are measured. Body image and eating disorders were measured using Contour Drawing Figure Rating Scale and eating Disorders Diagnostic Scale, respectively. Data analysis is done by Chi-Square with $\mathrm{p}<0.05$.

\section{RESULT}

Almost all of the respondents are having a negative body image (70.6\%). The respondents who have eating disorders were $52,7 \%$. Majority of them are also having an eating disorder (66.2\%). Chi-Square analysis shows a significant relationship between body image and eating disorders $(p=0.000)$.

\section{CONCLUSION}

There is a significant relationship between body image and eating disorders. We need an early management for negative body image perseption to avoid eating disorders in adolescent aged 15-19 years old.

Keywords : body image, body mass index, adolescent, eating disorders

\section{PENDAHULUAN}

Banyak remaja yang merasa tidak puas dengan penampilan dirinya. Hal ini akan menyebabkan para remaja mengalami gangguan makan atau eating disorders yang salah satunya diakibatkan oleh konsep persepsi tubuh seseorang yang buruk (persepsi negatif) dan ketidakpuasan terhadap tubuh yang dimiliki sehingga dapat menimbulkan dorongan untuk menjadi lebih kurus dari tubuh yang dimiliki saat ini. ${ }^{(1)}$ Dalam satu dekade terakhir, prevalensi penderita eating disorders di Asia Tenggara mengalami peningkatan yang signifikan yaitu dari $0,46 \%$ menjadi $3,2 \%$, di Indonesia prevalensi penderita eating disorders adalah sebanyak $37,3 \%$. $^{(2)}$ Banyak remaja yang merasa tidak puas dengan penampilan dirinya. Hal ini akan menyebabkan konsep persepsi tubuh yang buruk (persepsi negatif) dan ketidakpuasan terhadap tubuh yang dimiliki sehingga dapat menimbulkan dorongan untuk menjadi lebih kurus dari tubuh yang dimiliki saat ini. Media dan lingkungan menanamkan persepsi bentuk tubuh ideal adalah tubuh yang kurus. Hal ini menyebabkan remaja merasa tidak percaya diri dan merasa tidak puas terhadap bentuk tubuhnya sendiri. ${ }^{(3)}$

Mayoritas remaja laki-laki maupun perempuan memiliki persepsi negatif dengan merasa penampilan dan keseluruhan tubuhnya tidak menarik dan tidak memuaskan. Jika hal ini berlangsung terus-menerus maka remaja akan mengalami depresi yang akan meningkatkan persepsi tubuh negatif sehingga menimbulkan perilaku makan yang menyimpang atau bisa juga disebut dengan eating disorders. ${ }^{(4,5)}$

Persepsi tubuh (body image) adalah kumpulan sikap individu yang disadari dan tidak disadari terhadap tubuhnya, merupakan persepsi dinamis dari tubuh seseorang yang dibentuk secara emosional dan bisa berubah seiring dengan perubahan suasana hati, pengalaman, maupun lingkungan. Seseorang yang memiliki persepsi tubuh positif akan puas terhadap dirinya sendiri, merasa nyaman, dan percaya diri. Seseorang yang memiliki persepsi tubuh negatif menganggap tubuhnya tidak menarik, merasa malu, dan tidak percaya diri terhadap bentuk tubuhnya sendiri. ${ }^{(6,7)}$

Eating disorders (gangguan makan) 
adalah suatu sindrom yang ditandai oleh pola makan yang menyimpang terkait dengan karakteristik psikologik yang berhubungan dengan makan, bentuk tubuh, dan berat badan. Saat ini ada dua macam eating disorder (gangguan makan) yang diakui, yaitu anorexianervosa dan bulimia nervosa. Gangguan ketiga adalah "gangguan makan lain yang tidak ditetapkan" (EDNOS - eating disorders not otherwise specified) yang memasukkan beberapa variasi gangguan makan. Kebanyakan adalah mirip dengan anoreksia atau bulimia tetapi dengan karakter yang berbeda sedikit. Binge-eating disorder, yang menerima peningkatan dalam jumlah penelitian dan perhatian media dalam beberapa tahun belakangan ini adalah salah satu tipe EDNOS termasuk dalam DSM-V. $(7-9)$

Persepsi tubuh yang negatif yang dapat berkembang menjadi eating disorders banyak terjadi pada remaja. Menurut World Health Organization (WHO) masa remaja terbagi atas masa remaja awal (early adolescence) berusia 10-13 tahun, masa remaja tengah (middle adolescence) berusia 14-16 tahun dan masa remaja akhir (late adolescence) berusia 17-19 tahun. Remaja tergolong dalam vunerable group (rentan) karena merasa tidak puas dengan penampilan dirinya. Hal ini disebabkan karena tahap perkembangan psikologis yang dialami oleh remaja. Perubahan psikis pada masa ini adalah mulai memperhatikan penampilan, mengidentifikasikan diri dengan tokoh yang diidolakan, dan juga mulai bergantung pada teman-teman sebaya dan lingkungan sosial sehingga jika ada komentar negatif dari orang lain tentang penampilan fisik yang dimiliki, remaja akan lebih mudah merasa malu dan akan melakukan apapun agar mendapatkan komentar positif mengenai dirinya. ${ }^{(10-12)}$

Media massa memainkan peran luar biasa dalam komunikasi stereotip budaya tentang estetika persepsi tubuh. Beberapa percobaan menunjukkan bahwa pembentukan persepsi tubuh negatif dari paparan gambar atau iklan dari media massa meningkatkan ketidakpuasan seseorang terhadap tubuh yang dimiliki. Banyak survei cross-sectional dan longitudinal menemukan bahwa paparan media memprediksi ketidakpuasan tubuh, cita-cita tubuh yang kurus, dan gejala eating disorders di antara remaja dan dewasa muda, terutama pada remaja. ${ }^{(2,13)}$

Hal ini didukung dalam penelitian yang dilakukan oleh Jackson et al. ${ }^{(14)}$ pada tahun 2013 di Tiongkok dan Rodgers et al. ${ }^{(15)}$ yang melakukan penelitian pada tahun 2014 di Australia, bahwa mulai dari usia 14 tahun ke atas para remaja sudah mulai khawatir akan bentuk tubuhnya dan mulai mengurangi asupan makanan setiap hari dengan harapan dapat menjadi lebih kurus. Sebagian besar memiliki persepsi tubuh negatif lalu perlahan menunjukkan gejala depresi, hal ini sangat berisiko untuk berkembang menjadi eating disorders. $^{(16-18)}$

Namun, berbeda dengan penelitian yang dilakukan oleh Kurniawan et al.

di Bogor, bahwa tidak semua subjek yang memiliki persepsi tubuh negatif merasa cemas akan berat badan dan bentuk tubuh yang dimiliki saat ini, dan tidak memiliki dorongan atau keinginan untuk menurunkan berat badan sehingga tidak berisiko untyk berkembang menjadi eating disorders. Tujuan penelitian ini adalah menganalisis hubungan antara persepsi tubuh dengan eating disorders pada remaja usia 15-19 tahun.

\section{METODE}

\section{Rancangan penelitian}

Penelitian ini menggunakan desain observasional analitik secara potong lintang (cross-sectional) untuk menganalisis hubungan antara persepsi tubuh dan status gizi dengan eating disorders pada remaja. Penelitian dilakukan pada bulan November 2017.

\section{Subjek penelitian}

Subjek penelitian ini adalah seluruh siswa-siswi SMA Global Islamic School, Jakarta Timur. Kriteria inklusi pada penelitian ini adalah siswa-siswi yang berusia 1519 tahun sedangkan kriteria eksklusi pada penelitian ini adalah siswa-siswi yang sudah 
terdiagnosis eating disorder yang sedang menjalani terapi. Besar sampel didapatkan dengan menggunakan rumus berikut :

$\mathrm{n} \quad=\underline{\mathrm{Z}^{2}} \frac{\underline{\mathrm{p}} \times \mathrm{p} \times \mathrm{q}}{\mathrm{d}^{2}}$

dengan nilai $\mathrm{Z} 1,96$, prevalensi eating disorders $37,3 \%{ }^{(19)}$ dan $\mathrm{d}=0,05$.

Berdasarkan rumus tersebut maka didapatkan besar sampel minimal yaitu 173 . Untuk menghindari adanya data yang tidak lengkap atau hilang (drop out) maka peneliti menambahkan $15 \%$ dari jumlah sampel. Besar sampel penelitian ini adalah 199 subjek. Subjek diambil dari 12 kelas dengan masingmasing kelas berjumlah 24 orang. Subjek yang memenuhi kriteria inklusi dan eksklusi diberi penjelasan mengenai penelitian yang akan dilakukan dan diminta persetujuan untuk ikut dalam penelitian ini dengan menandatangani informed consent. Seluruh subjek di SMA Global Islamic School yang memenuhi kriteria inklusi dan eksklusi diambil sebagai subjek penelitian.

\section{Pengumpulan data}

Pengumpulan data dilakukan dengan cara wawancara menggunakan kuesioner meliputi data umur, jenis kelamin, dan status gizi. Eating Disorder Diagnostic Scale (EDDS) dinilai menggunakan 20 item pertanyaan, hasil nol menyatakan tidak ada eating disorders sedangkan hasil lebih dari atau sama dengan satu menunjukkan adanya eating disorders. Bila terdapat eating disorders maka akan dikelompokkan menjadi berbagai kriteria sesuai kelompoknya yaitu bulimia nervosa, Binge eating disorders, EDNOS dan anoreksia nervosa. ${ }^{(20)}$ Untuk menilai persepsi tubuh digunakan Contour Drawing Figure Rating Scale (CDFRS). ${ }^{(11)}$ Hasil nol menunjukkan subjek puas dengan bentuk tubuhnya/ persepsi tubuh positif sedangkan hasil positif/negatif menunjukkan subjek tidak puas dengan bentuk tubuhnya/ persepsi tubuh negatif.

\section{Analisis data}

Analisis data bivariat menggunakan metode Chi-square dan menggunakan program SPSS (Statistical Package for the Social Sciences) 21.0 for Windows dengan tingkat kemaknaan yang digunakan sebesar 0,05 .

\section{Kaji etik}

Penelitian ini telah lolos kaji etik dari Fakultas Kedokteran Universitas Trisakti dengan No.34/KER-FK/VII/2017.

\section{HASIL}

Subjek penelitian yang digunakan adalah seluruh siswa-siswi SMA Global Islamic School yang berjumlah 288 orang, sebanyak 20 orang absen pada haripenelitian dilaksanakan, maka jumlah yang hadir adalah 268 orang. Terdapat 67 responden yang tidak memenuhi kriteria inklusi yaitu yang tidak termasuk dalam kategori usia 15-19 tahun, sehingga didapatkan jumlah subjek penelitian sebanyak 201 orang.

Tabel 1. Distribusi Karakteristik Subjek Penelitian $(\mathrm{n}=201)$

\begin{tabular}{lcc}
\hline \multicolumn{1}{c}{ Variabel } & $\mathrm{n}$ & $\%$ \\
\hline Jenis Kelamin & & \\
Perempuan & 97 & 48,3 \\
Laki-Laki & 104 & 51,7 \\
Usia (tahun)--- (X+SD) & $17 \pm 0,5$ & \\
Status Gizi & & \\
$\quad$ Underweight & 40 & 19,9 \\
Normal & 117 & 58,2 \\
Overweight & 15 & 7,5 \\
Obese & 29 & 14,4 \\
Persepsi Tubuh & & \\
Negatif & 142 & 70,6 \\
Positif & 59 & 29,4 \\
Eating Disorder Diagnostic Scale & \\
Normal & 105 & 52,2 \\
Bulimia Nervosa & 50 & 24,9 \\
Binge-Eating Disorder & 19 & 9,5 \\
EDNOS & 23 & 11,4 \\
Anoreksia Nervosa & 4 & 2,0 \\
Eating Disorder & & 52,7 \\
Ya & 106 & 47,3 \\
Tidak & 95 & \\
\hline
\end{tabular}


Distribusi karakteristik subjek dapat dilihat pada tabel 1. Sebagian besar subjek penelitian berjenis kelamin laki-laki yaitu sebanyak 104 siswa (51,7\%). Rerata usia subjek penelitian $17 \pm 0,5$ tahun. Terdapat sebanyak 142 siswa-siswi $(70,6 \%)$ yang memiliki persepsi tubuh negatif. Siswa-siswi dengan status gizi yang normal didapatkan sebanyak 117 orang $(58,2 \%)$. Sebagian besar responden masuk ke dalam kategori eating disorders yaitu 106 orang $(52,7 \%)$.

Tabel 2. Jumlah karakteristik subjek persepsi tubuh dengan eating disorders

\begin{tabular}{lcc}
\hline \multirow{2}{*}{ Variabel } & \multicolumn{2}{c}{ Eating Disorders } \\
& Ya $(\mathrm{n} / \%)$ & Tidak $(\mathrm{n} / \%)$ \\
\hline$\quad$ Persepsi Tubuh Negatif & & \\
$\quad$ Status Gizi & & \\
Underweight & $14(6,9)$ & $14(6,9)$ \\
Normal & $47(23,4)$ & $24(11,9)$ \\
Overweight & $11(5,47)$ & $5(2,48)$ \\
Obese & $22(10,9)$ & $5(2,48)$ \\
Persepsi Tubuh Positif & & \\
$\quad$ Status Gizi & & \\
Underweight & $0(0)$ & $10(4,97)$ \\
Normal & $1(1)$ & $46(22,9)$ \\
Overweight & $0(0)$ & $0(0)$ \\
Obese & $0(0)$ & $2(0,99)$ \\
\hline
\end{tabular}

Dari tabel 2 diatas terdapat 47 orang dalam kategori status gizi normal yang memiliki persepsi tubuh negatif dan eating disorders, 24 orang dalam status gizi kategori normal memiliki persepsi tubuh negatif namun tidak eating disorders. Terdapat 46 orang dalam kategori gizi normal dan memiliki persepsi tubuh positif namun tidak eating disorders, namun terdapat satu orang dalam kategori status gizi normal yang memiliki persepsi tubuh negatif dan eating disorders.
Tabel 3. Hubungan status gizi dengan persepsi tubuh

\begin{tabular}{lll}
\hline \multirow{2}{*}{ Variabel } & \multicolumn{2}{c}{ Persepsi tubuh } \\
& Negatif & Positif \\
\hline Status gizi & & \\
Underweight & $30(14,9)$ & $10(4,97)$ \\
Normal & $70(34,8)$ & $47(23,3)$ \\
Overweight & $15(7,46)$ & $0(0)$ \\
Obese & $27(13,4)$ & $2(0,99)$ \\
\hline
\end{tabular}

$\mathrm{p}<0,05 *$ berbeda bermakna ( Chi Square)

Pada tabel 3. terlihat bahwa terdapat hubungan yang bermakna antara status gizi dengan persepsi tubuh dengan nilai $p=0,000$.

Dari tabel 4. didapatkan adanya hubungan yang bermakna antara persepsi tubuh dengan eating disorders dengan nilai $\mathrm{p}=0,000$.

\section{PEMBAHASAN}

Subjek pada penelitian sebanyak 201 responden yang terdiri dari 104 orang lakilaki dan 97 orang perempuan. Pada penelitian ini dilakukan penghitungan status gizi dengan cara mengukur Indeks Massa Tubuh (IMT) pada 201 siswa-siswi SMA Global Islamic School menggunakan acuan pengukuran dari WHO South-East Asia dengan nilai $<18,5$ termasuk dalam kategori status gizi underweight, nilai 18,5-24,9 termasuk dalam kategori normal, nilai 25,0-27,0 termasuk dalam kategori overweight, dan nilai $>27,0$ termasuk ke dalam kategori obese. Sebagian besar status gizi responden adalah normal. Hal ini sesuai dengan penelitian yang dilakukan oleh Torres-McGeehee et al. ${ }^{(16)}$ dan Watkins et al. ${ }^{(21)}$ bahwa pada sebagian besar subjek penelitian didapatkan kategori status gizi normal pada remaja dibanding dengan

Tabel 4. Hubungan persepsi tubuh dan eating disorders

\begin{tabular}{|c|c|c|c|}
\hline \multirow{2}{*}{ Variabel } & \multicolumn{2}{|c|}{ Eating disorders } & \multirow[b]{2}{*}{ nilai $\mathrm{p}$} \\
\hline & ya & tidak & \\
\hline \multicolumn{4}{|l|}{ Persepsi tubuh } \\
\hline Negatif (n/\%) & $94(46,7)$ & $48(23,8)$ & \\
\hline Positif (n/\%) & $1(0,49)$ & $58(28,8)$ & $0,000 *$ \\
\hline
\end{tabular}


kategori status gizi yang lain.

Pada penelitian ini didapatkan adanya hubungan yang bermakna antara status gizi dan persepsi tubuh. Urutan persentase jumlah responden yang memiliki persepsi tubuh negatif dari yang paling tinggi adalah kategori status gizi overweight, obese, underweight, normal. Sebagian besar responden memiliki persepsi tubuh negatif. Terdapat 142 (70,6\%) responden yang memiliki persepsi tubuh negatif. Hal ini tidak sesuai dengan penelitian yang dilakukan oleh Thomas et al. ${ }^{(22)}$ bahwa sebagian besar responden memiliki persepsi tubuh yang positif, hal ini mungkin disebabkan terdapat perbedaan kategori usia dengan yang dilakukan oleh peneliti yaitu pada penelitian Thomas et al. ${ }^{(22)}$ sebagian besar responden adalah dewasa muda dan memiliki kepercayaan diri yang tinggi sehingga dalam setiap kategori status gizi, sebagian besar memiliki persepsi tubuh yang positif. Hasil penelitian yang dilakukan oleh peneliti menyatakan bahwa sebagian besar responden memiliki persepsi tubuh yang negatif, hal ini didukung oleh penelitian yang dilakukan oleh Bully et al. ${ }^{(23)}$, hal ini mungkin disebabkan pada penelitian Bully et al. ${ }^{(23)}$ dan penelitian ini sama-sama menggunakan kuesioner dan responden yang diteliti memiliki kategori usia yang sama yaitu pada kategori usia remaja. ${ }^{(23)}$

Pada tabel 4. Terlihat bahwa terdapat hubungan yang bermakna antara persepsi tubuh dengan eating disorders. Sebagian besar responden yang memiliki persepsi tubuh negatif mengalami eating disorders. Hal ini sesuai dengan penelitian yang dilakukan oleh Herpertz-Dahlmann et al. ${ }^{(24)}$ yang menyatakan bahwa jika persepsi tubuh yang negatif tidak diperbaiki atau diterapi maka lama kelamaan akan mengalami eating disordes karena persepsi tubuh memiliki pengaruh yang besar terhadap eating disorders. Hal ini sesuai karena kriteria usia dan jumlah populasi yang diteliti oleh Herpertz-Dahlmann et al. ${ }^{(25)}$ tidak jauh berbeda dengan kriteria usia yang dilakukan oleh peneliti yaitu pada usia remaja sampai dewasa muda.

Keterbatasan penelitian ini adalah desain yang digunakan adalah desain potong silang sehingga tidak dapat mengetahui hubungan sebab akibat. Selain itu pada penelitian ini tidak dianalisis mengenai tingkat pendidikan dan tingkat pendapatan orang tua dari subjek penelitian yang mungkin memengaruhi terjadinya eating disorder pada subjek penelitian ini. Penelitian ini hanya dilakukan pada satu SMA saja sehingga kemungkinan tidak dapat mewakili seluruh populasi remaja. Implikasi klinis dari penelitian ini adalah perlunya deteksi dini mengenai persepsi tubuh negatif yang bila dibiarkan berlanjut dapat menyebabkan terjadinya eating disorder terutama pada populasi remaja.

\section{KESIMPULAN}

Terdapat hubungan yang bermakna antara persepsi tubuh dan eating disorders dan terdapat hubungan yang bermakna antara status gizi dan eating disorders. Perlu pencegahan dini terjadinya eating disorder yang diakibatkan persepsi tubuh negatif terutama pada remaja.

\section{KONFLIK KEPENTINGAN}

Penulis menyatakan tidak ada konflik kepentingan.

\section{UCAPAN TERIMAKASIH}

Penulis mengucapkan terimakasih kepada Kepala Sekolah SMA Global Islamic School, Jakarta timur dan kepada seluruh subjek penelitian yang telah bersedia ikut berpartisipasi dalam penelitian ini.

\section{KONTRIBUSI KEPENGARANGAN}

RSA menyusun konsep dan rancangan penelitian, pengumpulan data, analisis data, interpretasi data dan menyiapkan makalah. PSP menyusun rancangan penelitian, interpretasi data, revisi makalah akhir untuk publikasi. 


\section{DAFTAR REFERENSI}

1. Pike KM, Dunne EP . The rise of eating disorders in Asia: a review. Int $\mathrm{J}$ Eat Disord 2015;3:33. doi:10.1186/s40337015-0070-2.

2. Perloff RM. Social media effects on young women's body image concerns: theoretical perspectives and an agenda for research. Sex Roles 2014;71:363-77. doi: 10.1007/ s11199-014-0384-6.

3. Guimera GL, Levine MP, Carracedo DS, et al. Influence of mass media on body image and eating disordered attitudes and behaviour in females: a review of effects and processes. Media Psychol 2010;13:387-416.

4. Vogt-Yuan AS. Body perceptions, weight control behavior, and changes in adolescents' psychological well-being over time: a longitudinal examination of Gender. J Youth Adolesc 2010;39:92739.doi:10.1007/s10964-009-9428-6.

5. Isra RI. Kelompok sebaya dan perilaku makan menyimpang remaja SMA di Jakarta. J Sosiol 2016;21:263-83.

6. Paratmanitya Y, Hadi H, Susetyowati. Citra tubuh, asupan makan, dan status gizi wanita usia subur pranikah. J Gizi Klinik Indon 2012;8:126-34.

7. Wilfley DE, Bishop ME, Wilson GT, et al.Classification of eating disorders: toward DSM-V. Int $\mathrm{J}$ Eat Disord 2007;40:S123-9.DOI:10.1002/eat.20436.

8. American Psychiatric Association. Diagnostic and statistical manual of mental disorders. Washington (DC). APA 2013.

9. Davison TE, McCabe MP. Adolescent body image and psychosocial functioning. J Soc Psychol 2007;146:15-30.

10. Allen KL. Early onset binge eating and purging eating disorders: course and outcome in a population-based study of adolescents. J Abnorm Child Psychol 2013;41:1083-96.

11. Kurniawan MY, Briawan D, Caraka R. Persepsi tubuh dan gangguan makan pada remaja. J Gizi Klinik Indon 2015;11:10514.
12. Tantiani T, Syafiq A. Perilaku makan menyimpang pada remaja di Jakarta. J Kes Mas Nas. 2008;2:255-62.

13. Rodgers RF, Paxton SJ, Chabrol H. Depression as a moderator of sociocultural influences on eating disorder symptoms in adolescent females and males. J Youth Adolesc 2010;39:393-402.

14. Jackson $\mathrm{T}$, Chen H. Risk Factors for disordered eating during early and middle adolescence: A two year longitudinal study of mainland chinese boys and girls. J Abnorm Child Psychol 2014;42:791-802.

15. Rodgers RF, Paxton SJ, McLean SA. A biopsychosocial model of body image concerns and disordered eating in early adolescent girls. J Youth Adolesc 2014;43:814-23.doi:10.1007/s10964013-0013-7.

16. Torres-McGehee TM, Monsma EV, Gay $\mathrm{JL}$, et al. Prevalence of eating disorder risk and body image distortion among national collegiate athletic association division ivarsity equestrian athletes. J Athl Train 2011;46:431-7.

17. Ousley L, Cordero ED, White S. Eating disorders and body image of undergraduate men. J Am Coll Health 2008;56:617-21. doi: 10.3200/JACH.56.6.617-622.

18. Hastuti J. Anthropometry and body composition of Indonesian adults: an evaluation of body image ,eating behaviours, and physical activity (dissertation). Brisbane: Queensland University of Technology. 2013.

19. Septiadewi D, Briawan D. Penggunaan metode shape questionnaire (BSQ) dan figure rating scale (FRS) untuk pengukuran persepsi tubuh remaja perempuan. J Gizi Klinik Indon 2010;33:29-36.

20. Herpertz-Dahlmann B, Dempfle A, Konrad K, et al. Eating disorder symptoms do not just disappear: The implications of adolescent eating-disordered behaviour for body weight and mental health in young adulthood. Eur Child Adolesc Psych 2015;24:675-84. doi.10.1007/ s00787-014-0610-3.

21. Watkins JH, Christie C, Chally P. Relationship between body image and 
body mass index in college men. J Am Coll Health 2008;57:95-9.

22. Thomas JJ, Crosby RD, Wonderlich SA, et al. A Latent profile analysis of the typology of bulimic symptoms in an indigenous pacific population: evidence of crosscultural variation in phenomenology. J Psychol Med 2011;41:195-206. doi:10.1017/S0033291710000255.

23. Bully P, Elosua P. Changes in body dissatisfaction relative to gender and age: the modulating character of BMI. The Spanish J Psychol 2011;14:313-22. doi:10.5209/rev_SJOP.2011.v14.n1.28.

24. Herpertz-Dahlmann B, Willie N, Holling $\mathrm{H}$, et al. Disordered eating behaviour and attitudes, associated psychopathology and health-related quality of life: results of the BELLA study. Eur Child Adolesc Psychiatry 2008;17:82-91.doi 10.1007/ s00787-008-1009-9.

25. Herpertz-Dahlmann B, Dempfle A, Konrad K, et al. Eating disorder symptoms do not just disappear: The implications of adolescent eating-disordered behaviour for body weight and mental health in young adulthood. Eur Child Adolesc Psych 2015;24:675-84. doi.10.1007/ s00787-014-0610-3. 